\title{
Corrigendum: Mercury Accumulation in Marine Sediments - A Comparison of an Upwelling Area and Two Large River Mouths
}

\section{OPEN ACCESS}

Approved by:

Frontiers Editorial Office,

Frontiers Media SA, Switzerland

*Correspondence:

Sara Zaferan

s.zaferani@tu-braunschweig.de

Specialty section

This article was submitted to

Marine Biogeochemistry,

a section of the journal

Frontiers in Marine Science

Received: 06 October 2021

Accepted: 11 October 2021

Published: 28 October 2021

Citation:

Zaferani S and Biester H (2021) Corrigendum: Mercury Accumulation in Marine Sediments - A Comparison of an Upwelling Area and Two Large

River Mouths.

Front. Mar. Sci. 8:790338 doi: 10.3389/fmars.2021.790338

\section{Sara Zaferani ${ }^{\star}$ and Harald Biester \\ Institute for Geoecology, Environmental Geochemistry Group, Technische Universitaet Braunschweig, Braunschweig, Germany}

Keywords: mercury accumulation, marine sediment core, river, upwelling, algal scavenging

\section{A Corrigendum on}

Mercury Accumulation in Marine Sediments-A Comparison of an Upwelling Area and Two Large River Mouths

by Zaferani S and Biester H (2021). Front. Mar. Sci. 8:732720. doi: 10.3389/fmars.2021.732720

In the original article, there was a mistake in Figure 2 as published. The figure was a duplication of Figure 4. The correct Figure 2 appears below.

The authors apologize for this error and state that this does not change the scientific conclusions of the article in any way as the discussions and conclusions were based on the correct figure. The original article has been updated.

Publisher's Note: All claims expressed in this article are solely those of the authors and do not necessarily represent those of their affiliated organizations, or those of the publisher, the editors and the reviewers. Any product that may be evaluated in this article, or claim that may be made by its manufacturer, is not guaranteed or endorsed by the publisher.

Copyright (c) 2021 Zaferani and Biester. This is an open-access article distributed under the terms of the Creative Commons Attribution License (CC BY). The use, distribution or reproduction in other forums is permitted, provided the original author(s) and the copyright owner(s) are credited and that the original publication in this journal is cited, in accordance with accepted academic practice. No use, distribution or reproduction is permitted which does not comply with these terms. 


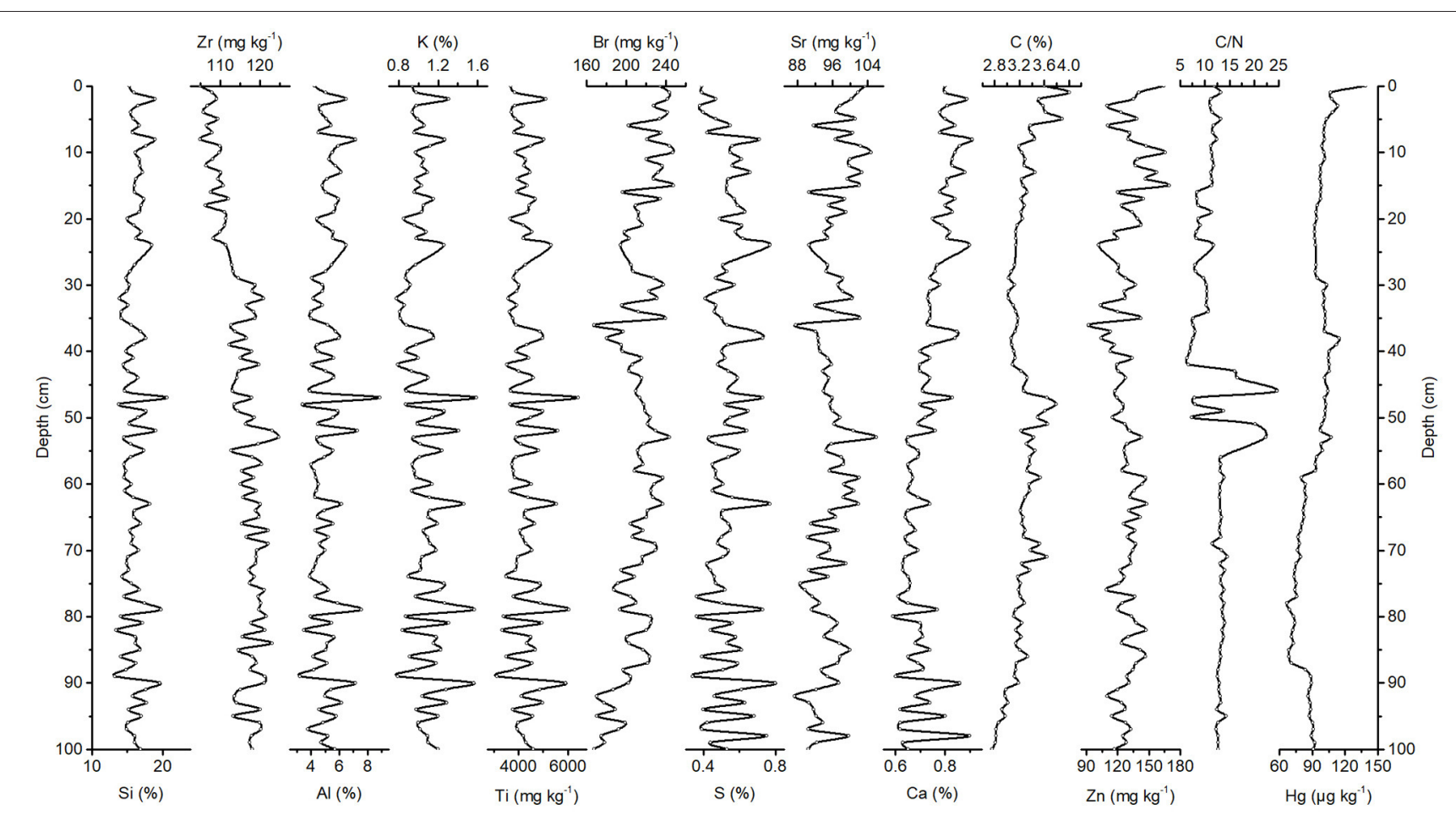

FIGURE 2 | Downcore records of Si, Zr, Al, K, Ti, Br, S, Sr, Ca, C, Zn, and Hg concentrations and C/N ratios of Congo Basin sediments. 